\title{
A PRÁTICA MISSIONÁRIA JESUÍTICA NO ESTADO DO MARANHÃo E GRÃO-PARÁ (SÉCULO XVII)
}

\section{THE JESUIT MISSIONARY PRACTICE IN THE STATE OF MARANHÃO AND GRÃO-PARÁ (17TH CENTURY)}

\section{Benedita do Socorro Santos de Sousa ${ }^{1}$ Antonio Nogueira de Sousa ${ }^{2}$}

\section{RESUMO}

A Companhia de Jesus nasce no seio da Igreja Católica para combater o protestantismo e, por meio da missionação, evangelização e educação, se torna a maior Congregação de ensino. A instrução, no Norte do Brasil, nos séculos XVII-XVIII, se desenvolve a partir de dois processos: a catequese (assistência e cristianização) e o ensino sistemático (Casas ou Colégios). Os jesuítas assumem as Missões no Maranhão e Grão-Pará através de Alvará de 25 de julho de 1638, e sua proibição de ensinar em escolas e aldeias são transcritas no Decreto de 28 de junho de 1759 com expulsão no mesmo ano (Bettendorff, 1910, 1990; Berredo, 1749; Chambouleyron, 2007; Arenz, 2009; Trigueiros, 2014). 0 estudo tem como principal objetivo caracterizar a importância das práticas missionárias jesuítas no estado do Maranhão e Grão-Pará (1638-1693). Abordagem consta de fenomenologia hermenêutica voltada ao estudo da experiência vivida (VanManen, 1997) sobre análise de documentos secundários (mais objetivos) (Ferrarotti, 2013) em comparação histórica (Laverty, 2003). Concluímos que o ensino e a educação no Maranhão e Grão-Pará se ergueram por meio da catequese ao ensinar os nativos da terra, com criação de vocabulários e compêndios para auxiliar os jesuítas no local, e do ensino sistemático na instrução aos filhos dos colonos portugueses e demais religiosos.

Palavras-chave: educação catequese missão jesuítica Estado do Maranhão-Grão-Pará

\section{ABSTRACT}

The Company of Jesus, born within the Catholic Church to fight against Protestantism, through mission, evangelization and education became the largest teaching Congregation in the world.

\footnotetext{
${ }^{1}$ Doutora em Ciências da Educação - Membro Colaboradora no Centro de Investigação Educação e Psicologia - Ciep/ Uevora- Portugal. Ver https://orcid.org/0000-0003-2262-2321 e Email dra.bsms@gmail.com

${ }^{2}$ Doutorando em Gestão de Empresas - Universidade de Coimbra-Portugal. Ver https://orcid.org/0000-0002-12986431- Email dr.ansousa@gmail.com -
} 
Education in northern Brazil, in the 17th and 18th centuries, developed from two processes: catechesis (assistance and Christianization) and systematic teaching (Houses or Colleges). The Jesuits would take up the Missions in Maranhão and Grão-Pará through the Alvará of July 25, 1638, and the forced suspension of all their teaching activities in schools and villages would come out by the Decree of June 28, 1759, with their expulsion in the same year (Bettendorff, 1910, 1990; Berredo, 1749; Chambouleyron, 2007; Arenz, 2009; Trigueiros, 2014). The main objective of this study is to characterize the importance of Jesuit missionary practices in the state of Maranhão and Grão-Pará (1638-1693). The research followed a hermeneutic phenomenological approach focused on the study of lived experience (VanManen, 1997), analysis of secondary (more objective) documents (Ferrarotti, 2013) and historical comparison (Laverty, 2003). We conclude that teaching and education in Maranhão and Grão-Pará were raised through catechesis in teaching the natives, with the creation of vocabularies and compendiums to assist Jesuits in the area, and systematic teaching of the children of Portuguese settlers, and the instruction of other missionaries as well.

Keywords: education catechesis Jesuit mission State of Maranhão-Grão-Pará

\section{1-Introdução}

A partir das formações iniciais da Ordem dos Jesuítas, em 1540, surgiram novas formas organizadas de vida religiosa, nas quais atividades caritativas extramuros poderiam ser combinadas com devoção e oração (VANDERSTRAETEN, 2014; O’MALLEY, 2016). Neste aspecto, no Maranhão e Grão-Pará, a instrução e a prática missionária jesuíticas estiveram constantemente presentes na ampliação de povoamento e colonização de índios e moradores em que o objetivo era a concretização da fé; deste modo, demonstravam a sua união entre a Igreja Católica e os jesuítas. Ainda assim, esta união era intimamente confirmada através do quarto voto, que significava obediência ao Papa, dado que a diferenciava das demais congregações (O'MALLEY, 2000).

O ensino e educação no Maranhão e Grão-Pará tiveram o seu início com o Padre Claudio de Abbeville, Capuchinho, que veio acompanhar LaRavardiére em missão de povoamento da cidade de São Luiz no Maranhão, em 24 de julho de 1611, e também com os demais religiosos Capuchinhos ou Barbadinhos que de imediato começaram a ensinar os índios. Com a derrota dos franceses, pelos portugueses, entre 1614 a 1615, e pelo fato da Ilha do Maranhão pertencer a Portugal, os religiosos Capuchinhos ou Barbadinhos regressaram a França (BETTENDORFF, 1910, 1990).

Com efeito, entre 1615 e 1618, o ensino passou a ser ministrado pelos jesuítas Manuel Gomes (pregador) e Diogo Nunes (conhecedor da língua do Brasil), que efetuavam os trabalhos com bastante empenho, mas em casa provisória, na Ilha do Maranhão. Entretanto, em março de 1618, os jesuítas tiveram de retornar a Pernambuco por ordem de seus Superiores (LEITE,1940), já que haviam cumprido a tarefa de guiar os índios na batalha contra os franceses no território local.

Em 5 agosto de 1624, os indígenas passaram a ser dirigidos pelos Franciscanos no Estado 
do Maranhão através de Frei Cristóvão de Lisboa, que exerceu o cargo de Superior dos Franciscanos, no Estado do Maranhão, para edificar as instalações dos Frades Menores com ações de evangelização, no labor da catequese, e de visitar às missões dos índios aldeados.

Frei Cristóvão de Lisboa edificou a primeira Casa dos Franciscanos Capuchinhos portugueses - o Convento de Santa Margarida, em São Luiz no Maranhão - exatamente no local onde estiveram albergados os Capuchinhos franceses, dado que, entre 1624 a 1627, os Franciscanos Capuchinhos portugueses administravam as aldeias dos índios nos regimes temporal e espiritual. Entretanto, os vários incómodos provocados pelos portugueses (colonos) ao quererem, constantemente, a administração dos índios levou aqueles missionários à decisão de se afastarem temporariamente deste dever.

Todavia, os jesuítas viriam a assumir as Missões no Maranhão e Grão-Pará através de dois documentos jurídicos: o Alvará de 28 de julho de 1638 concedido no governo de Felipe IV e a Patente de Roma de 3 de junho de 1639, ambos nomeavam Luiz Figueira (c. 1575-1643) "Superior de toda a missão quer dizer de todas as Residências ou Colégios que a Missão pudesse vir a fundar" (LEITE, 1940, p. 66).

Em contraste com as ordens religiosas contemplativas, as congregações ativas estavam envolvidas em atividades terrenas de algum tipo. Em parte, grande número das congregações ativas passou a respeitar as regras de proveniência franciscana, agostiniana ou jesuíta (VANDERSTRAETEN, 2014).

No âmbito deste estudo, o principal objetivo consistiu em caracterizar a importância das práticas missionárias Jesuítas no estado do Maranhão e Grão-Pará (1638-1693).

0 artigo encontra-se organizado em cincos capítulos. Na sequência deste primeiro capítulo, introdução, o segundo capítulo define a dinâmica do ensino e educação na missão jesuítica, o terceiro capítulo o ensino e a prática no Maranhão e Grão-Pará, em que atende ao âmbito teórico do estudo. 0 quarto capítulo diz respeito à metodologia e faz uma descrição da abordagem e método no âmbito científico. Por último, são apresentadas a discussão e conclusão.

\section{2-Ensino e educação na missão jesuítica}

A experiência no Novo Mundo, no entanto, teve um impacto não apenas em suas estratégias missionárias, mas também em seu desenvolvimento espiritual (MALI, 1996). 0 missionário jesuíta levou consigo estes valores para os recantos remotos da América do Norte e do Sul (REFF, 2005), haja vista que, o fim desta Companhia foi percorrer as mais diferentes partes do mundo, no qual poderiam utilizar todos os meios possíveis de ajudar as almas, no instruir, pregar, confessar e evangelizar.

Com efeito, para fundamentar a prática missionária se tornaram consequentes e necessárias as atividades catequéticas como núcleo central da ação inaciana(MONSERRAT; BARROS; SCHMIDT-RIESE, 2017). Logo, é evidente que as práticas missionárias, também se propagavam 
entre as pregações e as celebrações, que se estabeleciam entre as expressões orais e os gestos para transmitir doutrinas ou atitudes e posicionamentos religiosos, morais e políticos (MASSIMI, 2009), igualmente,este encontro de instrução religiosa, fazia-se essencial, com o intuito de converter os indígenasà fé cristã.

A prática da missão jesuítica alcançou o desenvolvimento de povoamento e colonização que encontrou na Igreja Católica um instrumento de expansão e adaptações, fossem para o Oriente ou o Ocidente. Ainda assim, as práticas retóricas humanistas nesses diferentes reinos apresentam características semelhantes "entre os vocabulários institucionais usados na administração e nas práticas jesuítas de auto-responsabilização espiritual"(QUATTRONE,2015,p. 422), por tal motivo, foram admitidos jovens edificantes e talentosos que pudessem germinar através da Companhia, homens ao mesmo tempo virtuosos e sábios para cultivar e expandir a Ordem Jesuítica.

0 empreendimento educacional teve um grande impacto na estrutura física dos estabelecimentos da sociedade, o que os tornou distintivos para uma ordem religiosa. No entanto, coordenada com esta realidade foi a teoria educacional dos Studiahumanitatis: que a educação foi finalmente dedicada ao bem público (O’MALLEY, 2016; MIRANDA, 2009), dado que, os estudos humanistas revelavam o homem de expressão plena, a sua capacidade de esforço individual, talento e trabalho, e não, por privilégios concedidos por regimes monárquicos, castas ou razões sociais.

Arenz (2010) descreve, também, a relação da Sociedade de Jesus a sua missão entre Oriente e Ocidente, como bastante, diferença o seu trabalho apostólico principalmente voltados para o Oriente - isto é China, Japão e Índia - eram os mais preferidos pelos jovens jesuítas, sobretudo, em razão do suposto nível cultural elevado dos povos Asiáticos. Contudo, nestes países, vigoravam as religiões solidamente organizadas e dotadas de livros sacros, edifícios arquitetónicos grandiosos e de sacerdotes instruídos em outras religiosidades (LEITE, 1965).

Mas, para o Ocidente, ao se acreditar no pensamento de Leite (1965), as práticas missionárias no Brasil eram o papel em branco primitivo de quem não sabia ler nem escrever, o gentio imerso ainda nos lindes da magia e do animismo, no estágio da religião e do mito, não já a do livro. A obra de conversão iria estabelecer-se mais num plano prático do que doutrinário, mais de mudança de costumes que de fé.

Na verdade, o Brasil fez-se pela Companhia de Jesus, desenhado e contornado através do ensino e de suas práticas missionárias em conexão direta com a obra de conversão e evangelização dos Índios, em que efetivamente foram privilegiados os métodos adaptados às novas realidades encontradas, juntamente com meios alternativos, mas também amplamente pedagógicos, sobretudo para a catequese, como a música e o teatro (MONTEIRO, 2009).

Para Prudente (2017, p. 44), por exemplo, o "catecismo era escrito pelos e para os missionários, servindo como manuais para o trabalho de evangelização. Era por meio da oralidade que os indígenas acessavam o conteúdo do catecismo, geralmente com a intermediação do missionário", nomeadamente, a Ordem Jesuítica se propagava nas variedades dos lugares, de tempos e de 
pessoas se podia variar a ordem das horas dedicadas ao estudo para esta finalidade, se bem que, “a Companhia de Jesus foi o emblema mais representativo da transformação e realização da nova prática da catequese na sua atuação missionária, durante a primeira Idade Moderna"(AGNOLIN, 2012, p. 19), em particular, na segunda metade do século XVIII, os jesuítas já não eram considerados reputados para atender as expetativas dos Soberanos portugueses.

Certamente, pelo motivo da "língua geral usada então nas missões não correspondia mais àquela que os missionários tinham aprendido nos catecismos e nas gramáticas jesuíticas impressas" (MONSERRAT; ARENZ; PRUDENTE, 2018, p. 122), especificamente, estes acontecimentos decorriam da "incompreensibilidade do texto catequético tupi institucionalizado pelos jesuítas decorria da política linguística de longa duração, seguida pela Companhia de Jesus, de não alterar o texto catequético tupi, identificado com as obras impressas" (MONSERRAT; BARROS; SCHMIDT-RIESE, 2017, p. 90).

Então, percebemos também que a catequese estava ligada diretamente às práticas missionárias nas aldeias nos séculos XVI a XVIII, bem como, "as gramáticas, catecismos e dicionários eram redigidos ao longo de muitos anos de trabalho dos padres de língua"(PRUDENTE, 2017, p. 13), por tudo isto, os jesuítas, ao princípio, situavam-se na costa, à beira-mar ou a poucas léguas do litoral, não nos sertões distantes, onde a segurança dos padres ainda se apresentava precária e onde as subsistências, incluindo o trigo e vinho das missas, dificilmente chegavam longe dos portos marítimos (LEITE, 1965).

Depois, já nos séculos XVII e XVIII, principalmente a norte, devido ao fluxo do rio Amazonas, o conjunto de aldeias de catequese prolongava a costa até ao coração do continente sul-americano, com repartições de diversos institutos missionários ao longo dos grandes afluentes do rio Amazonas (LEITE, 1965), com destaque aos principais rios Xingu, Tocantins, Tapajós e Madeira, com o objetivo de "estabelecer uma padronização da língua indígena a ser usada na catequese dos índios na América portuguesa"(PRUDENTE, 2017, p. 34).

Nos Colégios da Companhia de Jesus evidenciou-se os traçados das Constituições de Santo Inácio, em especial a formação da Quarta Parte IV e o Ratio Studiorum (1599), ambos organizavam de forma pormenorizada os estudos e os códigos práticos de leis que facilitavam a uniformidade da organização viva.

O modus parisiensis, fortificou as estruturas da Ordem Jesuítica no ensino ao enriquecer os métodos de ensino com: declamações, interrogações, composições, repetições e disputas, e ainda, os conhecimentos ricos, amplos e variados dos que partilhavam junto à Ordem Jesuítica, em que, constituía um caso único na história da pedagogia.

Para além, a predominância da eficácia da educação e ensino firmaram-se, também, nos elementos de ordem moral (emulação, persuasão e repreensão). 0 termo “emulação," neste sentido, confirma-se com o texto de Lopes (2014) em sua obra intitulada A emulação e a pedagogia da Companhia de Jesus, tendo sido considerada um instrumento pedagógico que a Companhia de Jesus adotou para atingir o seu objetivo de conseguir educar os seus alunos com uma maior efici- 
ência, a nível científico, espiritual e humano.

Decerto, através da persuasão e da repreensão, porventura, a Sociedade de Jesus podia se estabelecer com relação aos estudos nos colégios através das Constituições os quais utilizavam como base para tais finalidades - as aulas que deveriam existir nos colégios da Companhia - "recomenda-se aqui somente que não falte a justa correcção aos de fora quando dela precisarem, mas nunca pelas mãos de algum da Companhia" (Constituições, art. 395, p. 111). Estas aulas, portanto, adaptavam-se na prática às novas condições de tempos e espaços, ao se referirem às ciências experimentais e aos idiomas vernáculos, que os possibilitavam a uma organização e desenvolvimento de abertura maior e flexível com relação a organização dos currículos.

No entanto, o ensino científico da Corporação Jesuíta adentrou na Província portuguesa através da Aula da Esfera, do Colégio Jesuíta de Santo Antão em Lisboa, certificando o ensino e a prática entre finais do século XVI e até à primeira metade do século XVIII com impacte na história da Ciência, dado que a Aula da Esfera possibilitou aos Colégios Jesuítas o estabelecimento de um melhor acesso a comunidades científicas nacionais e internacionais, que trouxeram qualidade ao ensino no qual transladou o fluxo de pessoas, pensamentos, instrumentos e livros que circundavam as missões jesuíticas.

Desta forma, o conhecimento científico estabeleceu no ensino e educação o processo de ciências que foram importantes na transnacionalidade dos países neste período. A Companhia de Jesus estava empenhada e inseriu a Aula da Esferaem seus Colégios Jesuítas, tendo beneficiado a Província portuguesa e também constituído procedimento relevante para a história da Ciência e agregado mais de três dezenas de docentes, cerca de um terço eram de outras nações, oriundos de alguns Colégios da Europa do Norte (ALBUQUERQUE, 1972; RODRIGUES, 1938, 1944; LEITÃO, 2008a, 2008b; OSÓRIO, 1986) e ainda, a filiação multinacional da Companhia de Jesus deu aos seus missionários acesso a praticamente todas as colónias portuguesas, espanholas e francesas (HARRIS, 2005).

A respeito de todas as limitações ou erros que lhe possam ser apontados, a Aula de Esfera, com destaque ao Colégio de Santo Antão, foi uma atividade escolar de importância e significado na cultura portuguesa do século XVII; efetivamente, era este o único curso onde se professavam as ciências tão intimamente ligadas à Matemática - numa época em que a cadeira universitária sobre esta ciência não tinha professores (ALBUQUERQUE,1972).

De acordo comLowney (2004), os jesuítas detinham o espírito de liderança e valores através de seus conhecimentos conseguiam obter mudanças em qualquer lugar no qual se encontrassem, isto é, com autoconhecimento conseguiram compreender as suas forças, fraquezas e valores. No geral, sua espiritualidade religiosa pode ser melhor caracterizada por seu compromisso com o seu trabalho no mundo do que por sua adesão muitas vezes um tanto artificial a uma das tradições monásticas (VANDERSTRAETEN, 2014). Portanto, a visão de mundo, com o seu engenho inovaram e adquiriram confiança, adaptaram mudanças importantes na educação, com amor trataram o próximo conjugando atitude fraterna, e também com heroísmo fortaleceram-se a si próprios e 
aos demais que os seguiram (LOWNEY, 2004).

Por conseguinte, a prática missionária jesuítica esteve sempre presente em todas as ações que evidenciavam a propagação da fé, ou seja, pela retórica na prática de evangelização (pregações, catecismos, vocabulários, gramática, entre outros) "bem como espaços de papel, tinta, aroma, perfume, e outros artefatos, para ajudar os intelectuais e oradores a organizar, a memorizar e a inventar novas Conhecimento" (QUATTRONE, 2015, p. 417).

Em suma, depois da expulsão dos Jesuítas, proibição do ensino e encerramento do Colégio de Santo Antão, procedeu-se ao fim das lições científicas na Aula da Esfera na Província portuguesa. De facto, os procedimentos do ensino mudaram e estabeleceram outra direção. Desta forma, a qualidade no ensino e educação decaiu, sendo perceptível que o mecanismo não era o mesmo quando comparado com a estrutura implementada pelos jesuítas aquando da sua administração do ensino.

\section{3-Ensino e prática no Maranhão e Grão-Pará}

O Alvará de 25 de julho de 1638 marca o início do processo germinativo sistemático do ensino e da educação no Maranhão e Grão-Pará, que na atualidade corresponde à região Amazónica, tendo determinado os estabelecimentos de ensino, administrações, pregações, evangelizações e seminários nos séculos XVII e XVIII. Com destaque a instrução que "não significa somente pensar o ensino da doutrina e das escolas nas aldeias de índios livres, espaços privilegiados da missão jesuítica [..], mas, o ensino dos filhos dos moradores e os primeiros intentos de formar noviços da terra" (CHAMBOULEYRON, 2007, p.78).

Desta forma, os estudos realizados por Luiz Figueira (c. 1575-1639) ao Pará, Tocantins e Xingu demonstravam que a atividade missionária necessitava de novos ajustes para poder ser aplicada no extremo norte, já que, no século XVI, os jesuítas trabalhavam com o deslocamento de índios e as aldeias catequéticas eram construídas para cristianização e civilização. Doutro modo, no século XVII, as Residências ou Colégios e as aldeias no Maranhão e Grão-Pará, correspondiam à parte Norte do Brasil, e os índios passavam a ser assistidos e cristianizados no seu próprio lugar, uma vez que o deslocamento seria somente dos inacianos para o local, já que a sua área "começava não longe dos baixos de S. Roque, aos 30ํㅜ 30" L. S., estendendo-se até o rio Vicente Pinson (Oyapock)" (BETTENDORFF, 1910, 1990, p. xii-xiii).

Com efeito, Luiz Figueira (c.1575-1643), já como Superior da Missão no Maranhão e Grão-Pará detalhava em carta, ao Reino, o número de jesuítas, conventos e outros religiosos que estavam a praticar as suas obras de evangelização no Norte.

A Carta de Luiz Figueira, de 4 de setembro de 1639, mencionava o número de jesuítas e de religiosos de outras ordens: "Companhia de Jesus 3, Ordem de Nossa Senhora do Carmo (São Luís) 12, Ordem de Nossa Senhora do Carmo (Belém) 7, Ordem de São Francisco 5 num total de 27 missionários" (AMORIM, 2005, p. 270). 
Portanto, Luiz Figueira (c.1575-1643), ao constatar a ausência de missionários no Maranhão e Grão-Pará, admitiu que a missão não seria uma tarefa nada fácil, dado que tinha que recorrer a outros Colégios para atrair noviços ao Maranhão, e mesmo assim, as dificuldades enfrentadas não o impediram de desenvolver o seu trabalho e que os seus sucessores o continuassem após a sua morte em 1643.

Os Colégios no Maranhão e Grão-Pará começaram a se estruturar a partir de terrenos cedidos aos próprios jesuítas para as suas construções de Casas, que posteriormente foram elevadas a categoria de Colégios e tão somente não chegaram a titularidade de Universidade, pelo fato do Conde de Oeiras assinar o decreto de impedimento dos jesuítas de leccionar em todo o Reino, por outro lado, se isto não tivesse acontecido teríamos duas Universidades no extremo Norte - uma no Maranhão e outra no Grão- Pará tão logo no início do século XVIII,já que o Colégio da Baía no Estado do Brasil se intitulava o Colégio Máximo da Província e aguardava somente o parecer de Roma para tal titularidade igual à da Universidade de Évora.

\section{1- A Casa do Maranhão intitulada Nossa Senhora da Luz (1626-1761).}

A Casa do Maranhão, em 1626, é intitulada Nossa Senhora da Luz, por Luiz Figueira (c. 1575-1643) na cidade de Anindiba no Estado do Maranhão. Terreno localizado a "uma légua de terra [..] no centro da Ilha, a 5 légua da cidade" (LEITE, 1940, p.53).

Nesta instituição, Luiz Figueira (c. 1575-1643) ministrou os estudos de Latim e Humanidades até que foi fechada devido a sua morte, em 1643, sendo "reaberta pelo Padre Francisco Veloso, em 1652 e confirmada, logo pelo Padre António Vieira, e com as Artes e Cartapácios, que os jesuítas distribuíam gratuitamente aos alunos" (LEITE,1943, p. 263).

Em 1655, o Latim, Humanidades e Retórica eram denominação de Escolas Gerais, dado que 44 alunos já frequentavam Humanidades, distribuídos entre os alunos da casa (futuros missionários jesuítas) e os alunos externos (cargos públicos) (LEITE, 1943). De forma idêntica se ensinava o Latim nos pequenos Seminários de Guanaré e Parnaíba ambos dependentes da Casa do Maranhão. Nela funcionou o ensino rudimentar de aprendizagem mecânica, designado por Escolas de Artes e Ofícios, sob a supervisão do padre António Vieira (1653-1656).

Em 1661, o padre António Vieira (1658 a 1661) já como Superior e Visitador das Missões no Maranhão e Grão-Pará é expulso pelos portugueses (colonos) e entregue à Inquisição na cidade de Lisboa, o qual deveria ser mantido incomunicável até que todas as acusações a ele impostas fossem esclarecidas. Por tudo isto, Bettendorff (1625-1698) somente assumiria a Casa do Maranhão, já então como Reitor, entre 1674 a 1680, e nesse período encontrou os seguintes instrutores: Irmãos coadjutores - João Fernandes; Marcos Vieira e Manoel da Silva; Pregador, Confessor e mestre de Latim - António Pereira; Mestres de gramáticas - Francisco Ribeiro e João Ribeiro; Humanidades e Latim - Antonio Soares e, ainda assim, Bettendorff (1674-1680) ministrou também Humanidades e Latim durante cinco anos e meio.

Em 1674, a Casa do Maranhão é elevada a categoria de Colégio Máximo do Maranhão com a 
sua expansão em seus estudos primeiramente de Humanidades, Filosofia e Teologia e em seguida no Curso de Artes, em que se promoviam as defesas públicas e as Colações de grau. Por tudo isto, o trabalho do Jesuíta Bettendorff (1674-1680) consolidou-se no Maranhão quando promoveu no Colégio Máximo do Maranhão a receção de autoridade eclesiástica - Bispo Gregório dos Anjos, em 1680, e posteriormente, o docente Padre José Ferreira, em 1688, - Prefeito dos Estudos da Universidade de Coimbra.

O Colégio Máximo do Maranhão crescia em graça e estudos, com 1713 alunos (internos) e 1730 alunos (externos) aos quais a instituição concedia os graus de Bacharel, Licenciado, Mestre e Doutor atribuídos segundo “os privilégios de Pio IV e Gregório XIII” (LEITE, 1943, p. 269). Sendo assim, os atos públicos de defesas e Colações de grau marcavam definitivamente o Colégio Máximo do Maranhão, em que "Bettendorff diziam em nada cediam a Coimbra e a Évora” (LEITE, 1943, p. 268). Contudo, dos grandes feitos do ensino e educação naquele Colégio restou somente a lápide do Século XVIII, comemorativa da criação da Sé do Maranhão, já que a Carta Régia encaminhada a Manuel Bernardo de Melo e Castro, em 11 de junho de 1761, tinha o seguinte escrito "também vos ordeno e mandeis logo demolir a catedral antiga que se acha arruinada, e em perigo de cair, deturpando a praça onde se deve estabelecer a nova catedral" (AMORIM, 2011, pp. 980981).

\section{2- A Casa do Pará intitulada de Santo Alexandre (1652-1759).}

A Casa de Santo Alexandre, em Belém do Pará, tinha como fundador e primeiro Superior da Casa o Padre João de Souto-Maior (1652-1653), e o ensino apontava a carência alargada de instrutores pelo que "a instrução inicial no Pará foi também mais instrumento de catequese do que propriamente ramo profissional de ensino" (LEITE, 1943, p, 271).

O jovem missionário Bettendorff (1625-1698) foi designado para a Aldeia de Mortigura (atual Vila do Conde e Barcarena), no Pará, em 1661, no que ensinava o ABC aos meninos, as doutrinas e pregações e quanto às classes perpassavam a leitura e a escrita, em seguida, de quinze em quinze dias, visitava os índios aldeados em Carnapió, depois seguiu em missão à aldeia dos Tapajós (Santarém) e a Gurupatiba (atual Monte Alegre).

Com tanto empenho, em 1662 o jovem missionário foi escolhido Superior da Casa do Pará, tendo exercido, a partir desta data, os mais altos cargos administrativos na Missão até 1693. A Casa de Santo Alexandre foi elevada à categoria de Colégio no mesmo período que a Casa do Maranhão, ou seja, ambas em 1674, já que, entre 1668 e 1674, Bettendorff (1625-1698) era Superior da Missão no Maranhão e Grão-Pará.

Os irmãos coadjutores instrutores no Colégio de Santo Alexandre eram: Marcos Vieira, Baltasar Campos e o Padre Salvador do Valle, dado que, a aula de instrução elementar não era permanente e parecia de pouca afeição ao público e aos Jesuítas. Contudo, o ensino secundário resumia-se com precisão ao ensino do Latim (Gramática e Humanidades), entretanto, no Colégio de Santo Alexandre, as Artes e Ofícios aparecem com maior destaque entre "os índios, negros e cafusos que 
tinham aprendido as artes ou ofícios de pedreiros, ferreiro, carpinteiro, escultor, torneiro, alfaiate, tecelões e canoeiros" (LEITE, 1943, p. 261).

Na cidade do Pará, o ensino circundava em torno dos que poderiam ou não servir nas tropas. De entre estes alunos somente estariam sujeitos a servir como soldados aqueles que a Congregação de Jesus julgasse inquietos para os estudos e mediante a indicação prévia do Reitor do Colégio ou do Prefeito de estudos do Colégio.

Em 1684, Bettendorff (1625-1698) e seus companheiros Missionários foram expulsos da Missão do Maranhão e Grão-Pará pelo facto dos inúmeros conflitos entre jesuítas e portugueses (colonos) revoltosos, tendo como mentor Manuel Beckeman, não aceitarem a situação temporal a que os índios estavam sujeitos sob a guarda dos Jesuítas. Assim, o ensino e a educação seriam interrompidos e Bettendorff e os seus companheiros somente retornariam ao Estado do Maranhão a partir de 1686, para depois serem expulsos em definitivo, em 1759.

O ensino Superior no Colégio de Santo Alexandre abriu somente após o retorno dos Missionários a partir de 1686 e nele constavam aulas de Filosofia, Teologia e Casos (Teologia Moral). o Caso de Teologia Dogmática reservou-se para o Colégio do Pará, em Gurupá.

No Pará, abriu o Curso Superior de Filosofia pelo Padre Superior Bento de Oliveira (16931696), já que, no Maranhão, não havia mais comodidade em abrir o Curso de Filosofia pelo que foram mandados para o Pará. Sendo assim, as festas académicas ou Colação de grau eram realizadas na Igreja de Santo Alexandre, em 1696 tinham como Padre Superior José Ferreira.

No Colégio de Santo Alexandre, durante este tempo, foram feitos exames aos cursistas, do mesmo modo dos aplicados pelo Padre David Fay nas Universidades da Europa, dado que, na instituição, houve "aulas de grego e hebreu, ao menos em casos particulares. [..] Humanidades, Retórica e a Língua Hebraica" (LEITE, 1943, p. 272). Portanto, tínhamos a Casa de Vigia em que as aulas abriram entre 1732 e 1735 e na qual se ensinavam as primeiras letras e o curso de latim, sendo os horários compatíveis com os demais Colégios do Brasil.

O Colégio de Santo Alexandre permaneceu no Pará, mas somente como Museu para recordar o grande Colégio que foi no período auge da Companhia de Jesus no Norte evidenciados no quadro 1 os estabelecimentos de ensino jesuíticos no Maranhão e Grão-Pará.

\section{Quadro 1}

Estabelecimentos Educacionais Jesuíticos no Estado do Maranhão e Grão-Pará

\begin{tabular}{|l|}
\hline Colégio de S. Luiz - Colégio de Nossa Senhora da Luz do Maranhão-1626-1652-1679 \\
\hline Colégio de Belém - Colégio de Santo Alexandre - 1652-1670-1681 \\
\hline Casa-Colégio de Vigia - separou-se juridicamente em 1740 do Colégio de Santo Alexandre-1731-1740 \\
\hline Casa-Colégio de Tapuitapera - não chegou a ser elevada a Colégio \\
\hline
\end{tabular}

Fonte: Franzen (2002). 
Portanto, o ensino e a educação vigoraram no extremo norte sob a tutela dos jesuítas até 28 de junho de 1759, data em que foram proibidos de ensinar nas escolas e aldeias e depois expulsos em 3 de setembro de 1759.

Os jesuítas eram insignes habilidosos em explorar e descrever com detalhes o terreno local, em virtude destas habilidades, logo, se destacavam em missões de Oriente a Ocidente, mas foi na América do Sul que os seus feitos lhe renderam uma maior prosperidade, pelo fato dos aborígenes ainda se encontrarem em forma primitiva de educação e ensino sistematizados. De acordo com o seu compromisso estabelecido pelo fundador Padre Inácio de Loyola teve se submeter os sacrifícios que a missão religiosa tinha ao oferecer. Assim, "os jesuítas foram libertados dos compromissos da vida comum, o que lhes permitiu ministrar individualmente em lugares distantes. Eles poderiam viver seus votos no ministério ativo para a Igreja de Roma"(VANDERSTRAETEN, 2014, p. 495).

Sendo assim, procuravam explorar o terreno local realizando os estudos de campo e, por este meio, confeccionavam os mapas, os vocabulários, as gramáticas e os compêndios a respeito da situação dos índios aldeados e não aldeados para posteriormente trabalharem na atividade missionária.

No Maranhão e Grão-Pará, os livros, que passamos a destacar para garantir uma uniformidade das atividades jesuíticas foram, em primeiro lugar, os de Luiz Figueira (c. 1575-1643): Arte da Língua Brasílica e o Memorial sobre as terras e gente do Maranhão, Grão-Pará e Rio das Amazonas, em segundo lugar, o de António Vieira (1653-1656) e, por fim, o de Bettendorff (1625-1698): Compendio da Doutrina Cristãa na Língua Portuguesa e Brasílica (1681); a Arte de Gramática da Língua Brasílica de Luiz Figueira (1687) e o Catecismo Brasílico da Doutrina Cristãa de Antônio de Araújo (1686). Estas obras eram consideradas de grande valia, dado que ensinavam a forma de como se proceder nas aldeias, o catecismo, a Língua Brasílica e a Doutrina Cristã.

Com efeito, o padre António Vieira (1653-1656) apropriou-se dos documentos deixados por Luiz Figueira (c.1575-1643) e começou a explorar de forma mais alargada o Maranhão e Grão-Pará, já que deveria adequar as línguas que se apresentavam, a cada extensão, variadas e complexas e que os jesuítas deveriam interpretar, acolher e ensinar a catequese.

Neste aspecto, Bettendorff (1625-1698) designa a segunda parte deste Compendio em que constam os princípios dos mistérios de nossa Santa Fé, para se ensinar à maneira de Diálogos dos Índios do Estado do Maranhão. Assim, segue o pequeno trecho deste trabalho em língua Portuguesa e Brasílica:

\section{Quadro 2}

Diálogos dos Índios do Estado do Maranhão

\begin{tabular}{|c|c|}
\hline Língua Portuguesa & Brasílica \\
\hline Mistérios de Nossa Santa Fé & IpóTupã \\
\hline $\begin{array}{c}\text { Esta he a Doutrina Christãa que todos os fiéis } \\
\text { Christãos, hão de saber, crer e comprir? }\end{array}$ & $\begin{array}{c}\text { IpóTupãAmboeçâbaopabinheChristãoetéremicua- } \\
\text { râma, cemierobiarâma, imoporâmabécecoú. }\end{array}$ \\
\hline
\end{tabular}

Fonte: Vellozo e Bettendorff (1800). 
Embora, os próprios nativos não tinham o alfabeto e dependiam da tradição oral para preservar as suas histórias e costumes, ficaram intrigados com o aparente poder mágico da escrita usada pelos cristãos, e isto, os tornou mais abertos aos missionários(MALI, 1996), de tal forma, os noviços jesuítas exercitavam as pregações e lições sacras no sentido de assegurar que o povo ficasse edificado, algo diferenciado do método escolástico, que neste caso, o domínio da língua vernácula era o principal instrumento para o ministério.

Bettendorff (1625-1698) também reimpressa a Arte de Gramática da Língua Brasílica de Luiz Figueira (1687) em que se confirmou na arte de falar ordenado e breve, composto por estudos feitos por homens da Companhia de Jesus do mais alto prestígio em letras da língua nativa (Anchieta, Nobrega, Almeida, Figueira, entre outros), os quais fertilizaram à custa de suores tão intenso trabalho, de modo que a língua nativa os obrigava à constante renovação de vocabulário e gramática, principalmente dos termos em desuso e outros adquiridos pelos próprios nativos, como na Arte de Gramática da Língua Brasílica de Luiz Figueira (1687) se apresenta: "não mudão o assento da mesma sílaba; e mais sílabas, que crescem se saem corridas, de tal maneira que não se faz assento em nenhuã delas; utIacá, Iucábo, Iucábo, Iucareme" (BETTENDORFF e FIGUEIRA 1687, p.167).

O Catecismo Brasílico da Doutrina Cristã de António de Araújo (1686), reimpresso por Bettendorff (1625-1698), forma a parte essencial da condução das regras na aplicação do Catecismo e que inclui a sua composição: os diálogos, o confessionário e cerimonial dos sacramentos.

Portanto, o labor catequético produziu aos inacianos as multivivências em Terras distantes, já que a Ordem Jesuítica era regida pelo quarto voto de obediência ao Papa, demonstravam assim no Estado do Maranhão uma de suas maiores habilidades, a adequação às línguas locais, que nos séculos XVI e XVII se tornou seu alicerce, mas que na segunda metade do século XVIII se evidenciou na sua proibição, prisão e expulsão dos Reinos.

\section{4-Método}

O método de pesquisa seguido neste estudo visou atingir o seu principal objetivo - caracterizar a importância das práticas missionárias Jesuítas no estado do Maranhão e Grão-Pará (16381698).Teve como base, o processo de investigação a partir da utilização de fontes hemerográficas (artigos de journal, revistas, publicações em periódicos, monografias) e arquivos documentais escritos (correspondência, alvará, inventários).

\section{Quadro 3}

Processo de organização do material coletado

\section{Material de Pesquisa}

1Material de Pesquisa sobre o Ma- Arquivo da Torre do Tombo; Arquivo ranhão e Grão-Pará encontrado em Ultramarino; Biblioteca Pública de Évooutros sítios (manuscritos, micro-fil- ra; Seminário Maior de Évora; Bibliotemagem, mapas, entre outros). ra; Seminário Maior de Évora; Bibliote-
ca Nacional de Portugal, entre outros.

Além de referência completa, resumo e algumas citações, em algumas fichas foram anotadas reflexões sobre os assuntos tratados em fichamento.

Fonte: descrição dos autores. 
De acordo com Aróstegui (2001), para tal, são utilizadas documentações hemerográficas, iconográficas, arquivo documental escrito e bases bibliográficas. Logo, nesta pesquisa foram estabelecidos os procedimentos metodológicos.

Para o efeito, a interpretação das análises documentais, osviés e pressupostos assinalados pelo pesquisador não são descartados, mas incorporados e essenciais à pesquisa (LAVERTY, 2003) dado que os documentos secundários (FERRAROTTI, 2013). No entanto, a condução da pesquisa favorece os princípios da literatura.

Os materiais coletados apresentavam-se nas bases informatizadas e não informatizadas, já que o procedimento de análise documental gera em torno de arquivos primários e secundários distribuídos de acordo com a seleção de autores e de palavras-chave relacionadas à temática.

Para a seleção de autores, incluiu historiadores e pesquisadores experimentados tanto no objeto de estudo como também em métodos e fontes de História da Educação, em que é possível identificar alguns traços comuns que permeiam seus textos, apesar das notórias diferenças de caráter individual, uma vez que o grupo de autores promove uma correlação entre os autores citados e presentes na referência bibliográfica.

As palavras-chave estavam em correlação aos documentos: hemerográficos, iconográficos e arquivos documentais produzidos pelos próprios jesuítas acerca do Maranhão e Grão-Pará. Portanto, o tratamento das fontes tem por base a seleção de autores, já que se formou a busca cuidadosa da linha de pesquisa que cada autor procurou trabalhar, tendo sido estabelecidas as seguintes temáticas derivadas das palavras-chave devido a sua frequente apresentação evidenciada pelo estudo: educação, catequese, missão jesuítica, Estado do Maranhão-Grão-Pará. Ainda como fontes documentais recorreu-se aos manuscritos encontrados nos arquivos e também à transcrição de certos manuscritos a partir de obras literárias transcritas ou não pelos autores, que também ofereceram elementos preciosos para o desenvolvimento deste estudo.

0 tema da investigação determinou a pesquisadesenvolvida a partir da abordagemfenomenológica hermenêutica, via que "é interpretativa e concentrada nos significados históricos da experiência e seus efeitos cumulativos e de desenvolvimento nos níveis individual e social" (LAVERTY, 2003, p.15), tanto requer a capacidade de ser reflexivo, perspicaz, sensível à linguagem, e constantemente aberto à experiência (VAN MANEN, 1997) quanto sensibilidade "para compreender o processo que produz a pessoa e o seu produto no âmbito de uma dada classe e a sociedade num dado momento histórico" (FERRAROTTI, 2013, p. 66).

VanManen $(2003 ; 2016)$ considera a descrição (textual) evocativa e estimulante de ações, comportamentos, intenções e experiências humanas, como são vivenciados no mundo da vida. E na visão de Barnacle (2004), o modelo de pesquisa, com base na noção de experiência vivida, forneceu uma base para os investigadores educacionais refletirem sobre sua própria experiência pessoal como educadores, teóricos da educação, gestores e decisores de política educacional.

Assim, ao evidenciar a abordagem hermenêutica correlacionada com as fontes primárias e as fontes secundárias, não se negligencia a mais corrente e aceita das tendências historiográficas, 
aquela que classifica as fontes em primárias e secundárias segundo sua aproximação direta ou indireta com os fatos históricos (BERRIO, 1976).

Costa (2010) adverte ainda para a qualificação desses documentos devido a vasta e variada utilização de fontes primárias, neste caso, dos textos jesuíticos, devido ao fato de que os documentos do passado não foram elaborados para o historiador, mas sim para atender a necessidades específicas do momento (BARCELLAR, 2008). No entanto, a validade dos documentos aferidos na investigação obteve uma melhor qualidade nestes procedimentos. Então, devem ser observadas regras para não se fazer do resgate de fontes um exercício de memória, mais digno de estarem em um museu da escola do que, propriamente, suscitar um debate académico (COSTA, 2010).

Por outro lado, aspecto relevante na abordagem hermenêutica é a identificação dos fatos. Tal leva a crer que, neste estudo, a investigação de aspecto histórico no ponto de vista da educação não se realiza sem o apoio dos fatos, dados e informações contidos nas fontes (PINSKY, et tal., 2008). Segundo Melo (2010), de posse dos dados obtidos com essas ações, é possível buscar uma aproximação com o autor, desvendar suas preocupações, tendências, ideologias, objetivos.

0 foco desta pesquisa é caracterizar a importância das práticas missionárias Jesuítas no estado do Maranhão e Grão-Pará (1638-1693). Neste caso, a prática missionária jesuíta é relevante para sistema educacional no extremo norte do Brasil, que corresponde atualmente à Amazónia legal.

Embora, a Companhia de Jesus tivesse sido uma ordem religiosa eminentemente dedicada ao ensino da juventude, que constituiu, efetivamente, um dos seus principais campos de atividade até à supressão em 1773, continua a ser ainda, uma das suas mais insistentes preocupações, depois da restauração de 1814 (ROCHA, 1936).

Desta forma, a investigação merece uma atenção especial, devido ser algo que mostra o processo para auxiliar na condução do conhecimento científico. Assim, a pesquisa desenvolvida mereceu uma atenção adequada por parte dos pesquisadores aorequerer alguns cuidados relativamente aoprojecto de pesquisa e valorização dos procedimentos metodológicos,tendo presente atender a metodologia de investigação necessária para tomar uma direção e conseguir realizar o que foi determinado pelo objeto de estudo.

\section{5-Discussão e Conclusão}

A contribuição desta pesquisa para a história da educação seguiu o método fundamentado a partir dos documentos encontrados, mas também em termos metodológicos procurou optar pelo método mais adequado ao seu objeto de estudo para sua análise em profundidade e maior compreensão da temática estudada.Contribuímos para o recente debate da prática missionária jesuíta tendo presente o referido porMaravall (1967, p. 47), "conhecer uma realidade histórica, captar seu sentido". Ainda assim, "na seleção e/ou opção por incorporar ou deixar disponível esse ou aquele documento em investigação educacional significa conferir-lhe a condição de documento histórico-pedagógico" (MELO, 2010, p. 15). 
Este artigo explora as práticas missionárias jesuítas, no Maranhão e Grão-Pará relativamente à atividade missionária. A prática missionária jesuíta, no século XVI, tinha o seguinte procedimento, os jesuítas trabalhavam com o deslocamento de índios, em aldeias catequéticas para cristianização e civilização. Posteriormente, no século XVII, a prática missionária jesuíta em relação ao índio registou mudança nos procedimentos dado que os índios passaram a ser assistidos e cristianizados no seu próprio lugar, pois o deslocamento seria somente dos inacianos para o local.E de acordo com MALI (1996), a prática missionária jesuíta ao estabelecer uma atividade missionária nos séculos XVI e XVII foi um resultado inevitável da exploração europeia na nova era que levou à descoberta de novas terras e povos que nada sabiam da fé cristã.

A catequese favoreceu os meninos e as meninas indígenas a ler e a escrever e foi relevante a pregação do evangelho através dos pioneiros, o Padre Claudio de Abbeville e os demais religiosos Capuchinhos ou Barbadinhos (1614-1615), logo após os jesuítas Manuel Gomes e Diogo Nunes (1615-1618), em seguida os Franciscanos - Frades Menores (1624-1627), e finalmente os jesuítas, em 1638, assumindo definitivamente a Missão no Maranhão e Grão-Pará (BETTENDORFF, 1910, 1990).

A prática missionária, através da pedagogia jesuítica, permitiu-lhes estudar o terreno, interagir com o dialeto local em que iriam ser construídos os aldeamentos para os índios/índias no ensino da catequese e a educação nos Colégios para os filhos dos moradores, seguindo "as características da PedagogíaInaciana as fórmulas de síntese entre teoria e prática, entre pensar e fazer, entre conhecer e sentir ou experimentar, entre razão e fé, entre aprender e exercitar ou praticar" (LABRADOR, 1992, p. 47).

Salientamos os registos transcritos de forma pormenorizada pelos próprios jesuítas que temos como um dos inúmeros exemplos: o Padre Luiz Figueira, em 1636, realiza uma inspeção no Pará, Tocantins e Xingu o que lhe possibilitou aprimorar a língua Tupi-guarani criando a Arte da Língua Brasílica - Gramática constituída através da linguagem dos povos indígenas do extremo norte - tornando possível a catequese dos índios no Maranhão e Grão-Pará, visto que a "catequese andava porém unida à defesa dos Índios, contra a sua dispersão e escravidão quer jurídica quer de facto" (LEITE, 1940, p. 68).

E ainda, em relação direta à obra de convenção e evangelização, a missão conduziu a educação através da catequese que utilizou como método os instrumentos de comunicação da linguagem local. Desta forma, foram criadas as Gramáticas, os Vocabulários e os Catecismos para uma melhor eficácia da aprendizagem.

Nesse sentido,foram importantes as inspeções dos incontáveis Superiores das Missões: Luís Figueira (1638-1643), António Veira (1658-1661), Bettendorff (1668-1674); (1690-1693) que, entre outros, foram praticantesda Doutrina Cristã pelas demais aldeias encontradas no Maranhão e Pará, dado que os resultados destas visitas, no geral, apontaram para o cumprimento e o sucesso da catequese. Logo que terminavam as inspeções, realizavam relatórios que encaminhavam aos seus Superiores informando dos sucessivos progressos locais, cada um no seu tempo. 
O ensino, portanto, era iniciado pela catequese que unia o ensino da doutrina cristã aos rudimentos de ler, escrever e contar através dos trabalhos jesuíticos em Casas provisórias, que com tanto empenho de organização e funcionamento, não tardou a criação da Casa de Nossa Senhora da Luz, na cidade do Maranhão, e a da Casa de Santo Alexandre, na cidade do Pará, ambas com instrutores jesuítas dotados de seus ministérios, pregações e ensino de catequese, tendo passado à categoria de Colégios, em 1674, e tão somente não chegaram a titulação de Universidade devido ao Decreto do Conde de Oeiras restringir o ato.

Todavia, o corpo docente jesuítico era escolhido nos mais diferentes campos de aprendizagens,recrutado sem exclusividade a diferentes nações, com critérios únicos de competência e eficiência, o que tornava a ordem dos jesuítas ímpar em relação às demais ordens quanto aos campos de atuação no terreno local, o firmamento e a estruturação de seus ministérios.

0 traçado de uniformidade em fazer em cada lugar o que se julgar mais eficaz para nele se progredir, a organização e o funcionamento dos Colégios ao fundamentar, especificamente, Constituições e Ratio Studiorum (1599),determinaram que os estudos e códigos de leis eram seguidos sem contestação pelos seus membros (Franca, 1952).

Finalmente, a responsabilidade da conservação e administração dos bens materiais nos Colégios e, principalmente, de se sustentar com os próprios rendimentos eram habilidades que se trabalhavam desde a sua base enquanto noviço jesuíta, haja vista que, os mais experientes repassavam as informações necessárias para os novatos com o intuito de dar prosseguimento ao trabalho apostólico, ou seja, o que se aprendeu na teoria na Escolástica era agora posto em prática.

\section{Referências}

AGNOLIN, Adone. Atuação missionária jesuítica na América portuguesa: a peculiar via renascentista, sacramental e tridentina à salvação no(s) Novo(s) Mundo(s). Tempo, v. 18, n. 32, p. 19-48, 2012.

AlBuQUERQUE, Luís de A "Aula de Esfera" do Colégio de Santo Antão no Século XVII. Secção de Coimbra LXX. Agrupamento de Estudos de Cartografia Antiga: Junta de Investigações do Ultramar, 1972.

AMORIM, Maria Adelina. A Missionação Franciscana no Estado do Grão-Pará e Maranhão (16221750). Agentes, Estruturase Dinâmicas, 2011. Disponívelem:<http://hdl.handle.net/10451/5393>. Acesso em: 05 fev.2013.

AMORIM, Maria Adelina. Os Franciscanos no Maranhão e Grão-Pará. Missão e Cultura na Primeira Metade de Seiscentos, 2005 Disponível em:<http://hdl.handle.net/10400.14/7280>. Acesso em: 12 jun.2017.

ARAÚJO, António de. Catecismo brasílico da doutrina christãa, 1686. Disponível em: <https://ar- 
chive.org/stream/catecismobrasili00ara\#page/n7/mode/2up>. Acesso em: 10 set. 2013.

ARCHIVUM RomanumSocietatisIesu. Carta de Bettendorff a Oliva de 25 de março de 1674 - Belém do Grão-Pará. Cód. Bras 26, ff. 35r-35v.

ARENZ, Karl Heinz Do Alzette ao Amazonas: vida e obra do padre João Felipe Bettendorff (16251698).Revista Estudos Amazônicos, v. n. 1, p. 25-78, 2010.

ARENZ, Karl Heinz. Agonia da Missão-ruínas do Estado: Uma carta do padre João Felipe Bettendorff (1674). Revista Estudos Amazônicos, 4, pp.145-164, 2009. Disponível em:<http://www.ufpa. br/pphist/estudosamazonicos/arquivos/artigos/6\%20-\%20IV\%20-\%201\%20-\%202009\%20 -\%20Documento\%20-\%20Karl\%20Arenz.pdf>. Acesso em: 01 set.2012.

ARÓSTEGUI, Júlio. La investigación histórica: teoría y método, 2001. Disponível em:<https://pt.scribd.com/doc/88483095/Arostegui-Julio-La-investigacion-historica-Teoria-y-Metodo. >Acesso em: 12 jul.2014.

ARQUIVO Histórico Ultramarino. Casa de Nossa Senhora da Assunção - Informação sobre o número de conventos do Maranhão e respectivos religiosos, Maranhão. Cx. 1, 1639, setem, 4.

ARQUIVO Histórico Ultramarino. Cópia de Alvará com força de lei sobre a administração das Aldeias do Grão-Pará e Maranhão, Maranhão, Cx. 1, 1638, Jul, 25.

ARQUIVO Nacional Torre do Tombo. Carta Régia sobre a edificação do Colégio dos Nobres em São Luís do Maranhão e a demolição da antiga catedral. Manuscritos do Brasil, no 51, fl. 73. 1761, Jun, 11.

BARCELLAR, Carlos. Fontes Documentais. Uso e mau uso dos arquivos.In: Fontes Históricas. São Paulo: Editora Contexto, 2008.

BARNACLE, Robyn. Reflection on Lived Experience in Educational Research. Educational Philosophy and Theory, v. 36, n. 1, p. 57-67, 1 jan. 2004.

BERREDO, Bernando Pereira de. Annaeshistoricos do estado do Maranhão, 1749. Disponível em:<https://archive.org/details/annaeshistoricos00berr>. Acesso em: 01 fev.2014.

BERRIO, Julio Ruiz. El Método Historico En La Investigación Historica de La Educacion. Revista Española de Pedagogía, v. 34, n. 134, p. 449-475, 14 mar. 1976.

BETTENDORFF, João Filipe \& FIGUEIRA, Luís. Arte de grammatica da linguabrasilica. Lisboa: Na Officina de Miguel Deslandes, na rua da Figueira, 1687. Disponível em: <http://etnolinguistica. wdfiles.com/local--files/biblio\%3Afigueira-1687- arte/figueira_1687_arte_brown.pdf>. Acesso 
em:12 jan.2018.

BETTENDORFF, João Filipe. Chronica da Missão dos Padres da Companhia de Jesus no Estado do Maranhão. Instituto Histórico Geográfico Brasileiro, Tomo LXXII, Rio de Janeiro: Imprensa Nacional, 1910.

BETTENDORFF, João Filipe. Crônica da missão dos padres da Companhia de Jesus no Estado do Maranhão. (2o ed.) Belém: Fundação Cultural do Pará Tancredo Neves, 1990.

CHAMBOUlEYRON, Rafael. Os Jesuítas e o ensino na Amazónia Colonial. Aberta. Brasília, v.21, n.78, pp.77-91, 2007. Disponível em: <http://www.emaberto.inep.gov.br/index.php/emaberto/ article/view/1242/1110>. Acesso em: 23 abr.2014.

CONSTITUIÇÕES da Companhia de Jesus anotadas pela mesma Congregação Geral 34 e Normas Complementares aprovadas pela mesma Congregação. Cúria Provincial da Companhia de Jesus. Braga: Livraria A.I 1997.

COSTA, Célio Juvenal. Fontes Jesuíticas e a Educação Brasileira. In: Fontes e Métodos em História da Educação. Mato Grosso do Sul: Universidade Federal da Grande Dourados, 2010.

FERRAROTTI, Franco. Sobre a ciência da incerteza. O método biográfico na investigação em ciências sociais. Lisboa: Edições Pedago, 2013.

FRANCA, Leonel. O método pedagógico dos jesuítas: o Ratio Studiorum. Rio de Janeiro: Livraria Agir editora, 1952.

FRANZEN, Beatriz Vasconcelos. Os Colégios jesuíticos no Brasil: Educação e civilização na Colónia (1549-1759). Brotéria Cristianismo e Cultura, v.155, n. 1, p. 69-90, julho, 2002.

HARRIS, Steven J. Jesuit Scientific Activity in the Overseas Missions, 1540-1773. Isis, v. 96, n. 1, p. 71-79, 2005.

LABRADOR, Carmen. Estudio Histórico-Pedagógico, In El Sistema de Educativo de la Compañia de Jesús, la Ratio Studiorum. Espanha: Universidad Pontificia de Comillas, 1992.

LAVERTY, Susann M. Hermeneutic Phenomenology and Phenomenology: A Comparison of Historical and Methodological Considerations. InternationalJournalofQualitativeMethods, v. 2, n. 3, p. 21-35, 2003.

LEITÃO, Henrique. O debate cosmológico na Aula da Esfera do Colégio de Santo Antão. SphaeraMundi: A Ciência na Aula da Esfera. Manuscritos Científicos do Colégio de Santo Antão nas coleções da BNP. Lisboa: Biblioteca Nacional de Portugal, 2008a. 
LEITÃo, Henrique. SphaeraMundi: A Ciência na Aula da Esfera. Manuscritos Científicos do Colégio de Santo Antão nas coleções da BNP. Lisboa: Biblioteca Nacional de Portugal, 2008b.

LEITE, Serafim. História da Companhia de Jesus no Brasil. Tomo IV. Rio de Janeiro: Instituto Nacional do Livro, 1943.

LEITE, Serafim. Luiz Figueira. A sua vida Heróica e a sua obra Literária. Lisboa: Agência Geral das Colónias, 1940.

LEITE, Serafim. Suma História da Companhia de Jesus no Brasil (Assistência de Portugal). Lisboa: Junta de Investigação do Ultramar, 1965.

LOPES, José, Manuel. A Emulação e a Pedagogia da Companhia de Jesus. I. Brotéria Cristianismo e Cultura, v.179, n. 2/3, p. 155-173, agost/setem, 2014.

LOWNEY, Chris. El Liderazgo al Estilo de los Jesuitas. Bogotá: Grupo editorial norma, 2004.

MALI, Anya. Strange Encounters: Missionary Activity and Mystical Thought in Seventeenth Century New France. History of European Ideas, v. 22, n. 2, p. 67-92, 1996.

MARAVALL, José. António. Teoria del saber historico. Madrid: Revista de Oliveira,1967.

MASSIMI, Marina. Estudos sobre a contribuição da Antiga Companhia de Jesus ao desenvolvimento dos saberes sobre o psiquismo humano no Brasil colonial. Revista de Pesquisa Histórica. n. 27. v. 2, p. 163-191, 2009.

MELO, José Joaquim Pereira de. Fontes e Métodos: Sua importância na Descoberta das Heranças Educacionais. In Fontes e Métodos em História da Educação. Mato Grosso do Sul: Universidade Federal da Grande Dourados, 2010.

MIRANDA, Margarida. Código Pedagógico dos Jesuitas. Ratio Studiorum da Companhia de Jesus [1599]. Regime Escolar e Curriculum de Estudos. Lisboa: Esfera do Caos, 2009.

MONSERRAT, Ruth.; ARENZ, Karl. Heinz.; PRUDENTE, Gabriel. O sinal da Cruz em um catecismo na língua geral da Amazônia [ 175- ]. v. 6, p. 120-141, 2018.

MONSERRAT, Ruth; BARROS, Cândida; SCHMIDT-RIESE, Roland. Usos discursivos dos parênteses em um catecismo jesuítico na língua geral da Amazônia ([175-]). Revista de Estudos da Linguagem, v. 25, n. 1, p. 85-110, 2017.

MONTEIRO, Miguel Correa. A Fundação de Colégios e o Esforço Missionário dos Jesuítas. Colóquio Internacional 450 anos de Modernidade Educativa. Évora: Universidade de Évora, 2009. 
O'MALLEY, John W. The Distinctiveness of the Society of Jesus. Journal of Jesuit Studies, v. 3, n. 1, p. 1-16, 2016.

O'MALLEY, John; DUMINUCO, Vicente S. J. How the First Jesuit Became Involved in Education. The Jesuit Ratio Studiorum. 400th. Anniversary perspectives, 2000. Disponível em: <https://ecommons. luc.edu/ignatianpedagogy/310>. Acesso: 24 abr 2014.

OSÓRIO, José Pereira. Sobre a História e Desenvolvimento da Astronomia em Portugal. História e Desenvolvimento da Ciência em Portugal. Volume I. Lisboa: Publicações do II Centenário da Academia das Ciências de Lisboa, 1986.

PINSKY, Carla, Bassanezíet tal. Fontes Históricas. São Paulo: Editora Contexto, 2008.

PRUDENTE, Gabriel de Cassio Pinheiro. Entre índios e verbetes: a política linguística na Amazônia portuguesa e a produção de dicionários em língua geral por jesuítas centro-europeus (17201759). p. 189, 2017.

QUATTRONE, Paolo. Governing Social Orders, Unfolding Rationality, and Jesuit Accounting Practices: A Procedural Approach to Institutional Logics. Administrative Science Quarterly, v. 60, n. 3, p. 411-445, 2015.

REFF, Daniel T. Soldiers of God: The Jesuits in Colonial America, 1565-1767. HispanicAmericanHistoricalReview, v. 85, n. 1, p. 129-130, 2005.

ROCHA, A. Os Colégios dos Jesuítas e a pedagogia da liberdade. Brotéria Revista Contemporânea de Cultura, v. 23, agost, 1936.

RODRIGUES, Francisco. A Acção crescente da Província Portuguesa (1560-1615). História da Companhia de Jesus na Assistência de Portugal. Tomo Segundo. Volume I. Porto: Livraria Apostolado da Imprensa, 1938.

RODRIGUES, Francisco. A provincia portuguesa no Século XVII (1615-1700). História da Companhia de Jesus na Assistência de Portugal. Tomo Terceiro. Volume I. Porto: Livraria Apostolado da Imprensa, 1944.

TRIGUEIROS, Antonio Júlio. Expulsão, Exílio e Supressão dos Jesuítas na Assistência Lusitana. InBi-Centenário da Restauração da Companhia de Jesus (1814-2014). Brotéria Cristianismo e Cultura. Lisboa: Brotéria, 2014.

VAN MANEN, Max. Investigación educativa y experiencia vivida: ciencia humana para una pedagogía de la acción y la sensibilidad. Editorial: S.A Idea Books, 2003. 
VAN MANEN, Max. Researching Lived Experience, Second Edition: Human Science for an Action Sensitive Pedagogy. Routledge, 2016.

VAN MANEN, Max. Researching lived experience: Human science for an action sensitive pedagogy. (2o ed.). London, Canada: The Althouse Press, 1997.

VANDERSTRAETEN, Raf. Religious activism in a secular world: The rise and fall of the teaching congregations of the Catholic Church. Paedagogica Historica, v. 50, n. 4, p. 494-513, 2014.

VELLOZO, José Mariano da Conceição. \& BETTENDORFF, João Filipe. Compendio da doutrina christãa na lingua portugueza, e brasilica, 1800. Disponível em: <http:// biblio.etnolinguistica.org/betendorf_1800_compendio>. Acesso em:12 jun.2015.

Artigo Recebido: 27/10/2020

Aprovado em: 25/11/2020

Publicação: Dezembro de 2020 